\author{
Military Technical College \\ Kobry El-Kobbah, \\ Cairo, Egypt
}

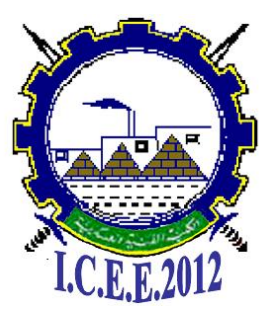

$6^{\text {th }}$ International Conference on

Chemical \& Environmental Engineering 29 -31 May, 2012.

\title{
CALCULATIONS OF DETONATION PARAMETERS FOR HIGH EXPLOSIVES USING DIFFERENT METHODS
}

\author{
J. Bogdanov*, R. Jeremić†, Z. Bajićł, R. Dimitrijević§ and Z. Veličkovićđ
}

\begin{abstract}
:
The detonation parameters can be calculated using different methods with satisfying accuracy. Different approaches of detonation parameters' calculations are used in many fields of engineering practice. The calculation results of detonation parameters using semi-empirical method and thermochemical model of detonation are presented in this paper. Both methods are applicable for CHNO high explosives, and with some approximations for CHNOAl high explosives. The calculated values using semi-empirical method have significantly better accuracy compared with the well-known Kamlet's method. The thermochemical model uses BKW equation of state with different sets of parameters. The detonation products are calculated using the free-energy minimization criterion. The computer program $\mathrm{XW}$ is developed, which is using both methods. The XW is developed using the Delphy ${ }^{\circledR} 6.0$, and it can be used on personal computers with operating system WindowsXP ${ }^{\circledR}$. The analyzed XW calculation results of detonation parameters have good correlation with experimental data.

Using the semi-empirical method, obtained average differences of calculation results for considered high explosives were $1.9 \%$ for detonation velocity and $4.5 \%$ for detonation pressure. In the calculations using thermochemical model, average differences of calculation results were $2.05 \%$ for detonation velocity and $5.73 \%$ for detonation pressure. In the case of most used high explosives for military purposes, the precision of calculation results is even higher.
\end{abstract}

* Assistant Professor, Department of Military Chemical Engineering, Military Academy, Pavla Jurišića - Šturma Street 33, Belgrade, Serbia, bjbogdanov@open.telekom.rs

$\dagger$ Professor, Military Academy, Pavla Jurišića - Šturma Street 33, Belgrade, Serbia, radun@mail.com

* Assistant Professor, Department of Military Chemical Engineering, Military Academy, Pavla Jurišića - Šturma Street 33, Belgrade, Serbia, zoran.bajic@va.mod.gov.rs

$\S$ Professor, Military Academy, Pavla Jurišića - Šturma Street 33, Belgrade, Serbia

II Assistant Professor, Department of Military Chemical Engineering, Military Academy, Pavla Jurišića - Šturma Street 33, Belgrade, Serbia, zlatevel@yahoo.com 


\section{Introduction}

In many aspects, the detonation parameters are the most important characteristics of high explosives. The most important detonation parameters are detonation velocity $\mathrm{D}$ and detonation pressure $\mathrm{p}$. There are many methods successfully developed for detonation characterization of high explosives, and many experimental values are widely published. But, in many cases it is very difficult to experimentally determine these values.

Many authors have managed to develop models for $\mathrm{D}$ and $\mathrm{p}$ calculations. There are many models based on semi-empirical approach $[1,2,3]$. Such models are based on simplified view on detonation process, but have surprisingly very high precision of calculation results for CHNO high explosives with initial densities within certain range. For example, the Kamlet's method has been often used for calculations of detonation parameters in the past decades [1]. The thermochemical approach in modeling of detonation is one of several ways to calculate detonation parameters with more detailed view on the process itself. The approach is based on simplified thermochemical view of chemical reactions during detonation process. The chemical decomposition of energetic material is considered as their very fast transformation into detonation products, with conservation of mass and energy. Many aspects are not necessarily considered, such as reaction kinetics, time scale etc. Despite that, such models show good correlation with experimental data and can be used for detonation modeling of the most military high explosives. Such models of detonation are presented in [4, 5, 6]. Computer program XW was developed based on the previously described approaches in modeling of detonation, both semi empirical and thermochemical. XW is used on personal computers with operating system WindowsXP ${ }^{\circledR}$.

The semi-empirical model [3] is based on the fact that the experimental values of the detonation parameters are proportional to the initial density of the explosive [1]. Experiments show that detonation velocity has linear dependence on initial density for all explosive charges above a critical diameter. Based on the equation of state (EOS) for gases, the pressure is proportional to the number of moles of gaseous detonation products $\mathrm{n}$. Therefore, it is assumed that detonation pressure is proportional to the square of initial density $\rho_{0}$.

In this model, detonation velocity and detonation pressure are calculated using the following equations:

$$
\begin{aligned}
& D=2264.1+7.7072 \rho_{0} \sqrt{n Q} \\
& p=0.00048 \rho_{0}^{2} n Q
\end{aligned}
$$

where:

- $\rho_{0}$, is the initial density of high explosive, expressed in $\mathrm{g} / \mathrm{cm}^{3}$,

- $\mathrm{n}$ is the total quantity of gaseous detonation products, in $\mathrm{mol} / \mathrm{kg}$,

- $\mathrm{Q}$ is the heat of explosion, in $\mathrm{kJ} / \mathrm{kg}$.

- D is the calculated detonation velocity in $\mathrm{m} / \mathrm{s}$, and

- $\mathrm{p}$ is detonation pressure in kbar.

The total quantity of gaseous detonation products $\mathrm{n}$ is calculated using the Avakyan's method [7], where 6 gaseous detonation products are considered $\left(\mathrm{H}_{2} \mathrm{O}, \mathrm{H}_{2}, \mathrm{CO}_{2}, \mathrm{CO}, \mathrm{O}_{2}\right.$ and $\left.\mathrm{N}_{2}\right)$. The solid carbon is also considered in detonation products, but is not used for further calculations. The heat of explosion Q is calculated according to Hess' law and using the thermochemical tables. 
In the thermochemical model there are considered 9 gaseous chemical species $\left(\mathrm{H}_{2} \mathrm{O}, \mathrm{H}_{2}, \mathrm{O}_{2}\right.$, $\mathrm{CO}_{2}, \mathrm{CO}, \mathrm{NH}_{3}, \mathrm{CH}_{4}, \mathrm{NO}$ and $\mathrm{N}_{2}$ ) and solid carbon in detonation products [6]. In the case of $\mathrm{CHNO}$ high explosives, the chemical reaction can be written as:

$$
\begin{aligned}
& \mathrm{C}_{a_{1}} \mathrm{H}_{a_{2}} \mathrm{~N}_{a_{3}} \mathrm{O}_{a_{4}} \rightarrow n_{1} \cdot \mathrm{H}_{2} \mathrm{O}+n_{2} \cdot \mathrm{H}_{2}+n_{3} \cdot \mathrm{O}_{2}+n_{4} \cdot \mathrm{CO}_{2}+n_{5} \cdot \mathrm{CO}+ \\
& +n_{6} \cdot \mathrm{NH}_{3}+n_{7} \cdot \mathrm{CH}_{4}+n_{8} \cdot \mathrm{NO}+n_{9} \cdot \mathrm{N}_{2}+n_{10} \cdot \mathrm{C}_{(s)}
\end{aligned}
$$

The composition of detonation products is calculated using the free-energy minimum criterion. The Becker-Kistiakowsky-Wilson equation of state (BKW EOS) is used for gaseous detonation products [4], and Cowan-Ficket equation [5] for solid carbon. The detonation parameters are calculated for CJ-state, where detonation velocity has minimum value.

The calculation results can be saved in corresponding file XWData.mdb, which can be further edited using Microsoft Office Access ${ }^{\circledR}$.

\section{Calculation results and discussion}

The calculations of detonation parameters were performed using both semi-empirical and thermochemical approaches. There were considered all major high explosives that are used for military purposes: cyclotrimethylene trinitramine (RDX or hexogene), cyclotetramethylene tetranitramine (HMX or octogene), trinitrotoluene (TNT), pentaerythritol tetranitrate (PETN), hexanitrohexazaizowurtzetane (HNIW), tetryl (TET), hexanitrostylbene (HNS), as well as their various mixtures with TNT or polymers.

\section{Results of semi-empirical method}

For the calculations using semi-empirical method 74 high explosives with different compositions and initial densities were considered. They were grouped according to their physical composition as:

- high explosives without other components (TNT, RDX, HMX, PETN, TET, HNS, nitromethane, nitroglycerine and DATB at different initial densities, or 27 different high explosives),

- explosive mixtures of RDX, HMX or PETN with TNT (32 high explosives),

- explosive mixtures of RDX, HMX or PETN with polymer binders (15 high explosives).

The analysis of calculated detonation parameters using equations (1) and (2) from semiempirical model showed very good correlation with experimental data [3]. Correlation coefficient of calculated and experimental values was $R^{2}=0.98$ for all considered explosive compositions. The average difference of calculation results for considered high explosives was $1.9 \%$ for detonation velocity and $4.5 \%$ for detonation pressure (Table 1 ).

The described semi-empirical model shows better accuracy than well-known Kamlet's method [1] and can be successfully applied in wider range of initial densities [3].

The best correlation is observed for considered explosive mixtures with TNT. In that case, there were no considered explosives with low initial densities, where many methods show low accuracy. Further analysis is needed for such explosives, especially with initial densities < $1.20 \mathrm{~g} / \mathrm{cm}^{3}$, where lower accuracy is expected.

\section{Results of thermochemical model}

In order to analyze calculation accuracy of the thermochemical model, there were considered 172 experimental detonation velocities and 129 experimental detonation pressures. Used 
parameters in BKW EOS are presented in Table 2. It was found that there is no single set of parameters for BKW EOS used in the thermochemical model for all considered high explosives. Such conclusions were also in similar models $[4,5]$.

According to analysis in [6], the corresponding set of BKW EOS parameters must be used in calculations for different high explosives, in order to obtain the best precision of results. The suggested usage of BKW EOS parameters depending on chemical composition of high explosive is presented in Table 3.

The analysis shows that, with the proper use of BKW EOS parameters, the good correlation of calculated and experimental detonation parameters can be obtained. The results are presented in Table 3. Average difference of calculated values for most of the considered high explosives is $<3 \%$ for detonation velocity and $<6 \%$ for detonation pressure. The accuracy of calculation is even higher for the most used military high explosives with initial density $>1$ $\mathrm{g} / \mathrm{cm}^{3}$, like different mixtures of RDX and TNT [8]. In some cases, the average difference is higher, where in the most cases it is $<5 \%$ for detonation velocity and $<10 \%$ for detonation pressure.

For example, the experimental and calculated detonation velocities and detonation pressures for RDX, TNT, HMX and TET are presented graphically on Figures 1 and 2. Calculated values are represented with lines, where dotted lines are for the results of semi-empirical, solid lines for thermochemical model and marks represent corresponding experimental values.

\section{Conclusions}

The presented analysis of both models of detonation show good accuracy of calculation results. Proper selection of BKW EOS parameters is necessary for the thermochemical model, and is suggested in this paper.

Low accuracy is mostly observed for high explosives with very low $\left(<1 \mathrm{~g} / \mathrm{cm}^{3}\right)$ or extremely high initial densities, as well as with high amount of inert components (polymer binders). Such behavior was previously observed also in $[1,4,5,7]$. One of the possible explanations is non-ideal behavior of detonation process, where reaction time-scale cannot be neglected. One of the further developments of the thermochemical model could be expansion with such approach, so the reaction kinetics would be considered.

The presented methods, incorporated in computer program XW, could be used for most high explosives for military use, especially for engineering purposes. Also, the methods could be used in early-stage developments of new high explosive compositions, where little or no data could be obtained. Main advantage in that field is very small amount of input data needed for calculations of detonation velocity and pressure, especially in the semi-empirical model.

Thermochemical model can be also further developed, where different EOS could be incorporated, expanded for more chemical species like $\mathrm{Cl}, \mathrm{F}, \mathrm{B}, \mathrm{Al}$ etc.

\section{References}

[1] M.J. Kamlet, et al., Chemistry of detonations, I-IV, J. Chem. Phys., Vol. 48, No.1 (1968).

[2] M.N. Makhov, V.I. Pepekin, Calculation of chemical composition of detonation products", Pol. J. Chem., 55 (1981), 1381.

[3] R. Jeremić, J. Bogdanov, Development of new model for high explosives' detonation parameters calculation, J. Serb. Chem. Soc, (2011), doi: 10.2298/JSC101206163J.

[4] C.L. Mader, Numerical Modeling of Explosives and Propellants, $3^{\text {rd }}$ ed., CRC Press, (1998). 
[5] M. Sućeska, Rheological and Detonation Properties of Cast Composite Plastic-Bonded Explosives (in Serbo-Croatian), CVTŠ KoV, Zagreb (1991).

[6] J. Bogdanov, Numerical Modeling of Energetic Material Detonation Process (in Serbian), MSc thesis, University of Belgrade, Faculty of technology and metallurgy, Belgrade (2009).

[7] Fizika vzryva (in Russian), Fizmatlit, Moscow (2002), L. I. Orlenko (ed.).

[8] J. Bogdanov, R. Jeremić, Z. Bajić, Detonation characteristics calculation of TNT/RDX high-explosive compositions (in Serbian), Proc. $3^{\text {rd }}$ Scientific Expert Conference OTEH, Military Technical Institute, October 7-9, Belgrade (2009).

Table 1 Average difference of calculation results using semi-empirical model [3]

\begin{tabular}{|c|c|c|c|c|}
\hline \multirow[t]{2}{*}{ No. } & \multirow[t]{2}{*}{ High explosive composition } & \multirow{2}{*}{$\begin{array}{c}\text { Number of considered } \\
\text { explosive } \\
\text { compositions }\end{array}$} & \multicolumn{2}{|c|}{$\begin{array}{c}\text { Average difference of } \\
\text { calculated values from } \\
\text { experimental }\end{array}$} \\
\hline & & & $\Delta \mathrm{D}, \%$ & $\Delta p, \%$ \\
\hline 1. & High explosives & 27 & 2.8 & 6.9 \\
\hline 2. & $\begin{array}{c}\text { Explosive mixtures with } \\
\text { TNT }\end{array}$ & 32 & 0.6 & 1.8 \\
\hline 3. & $\begin{array}{l}\text { Explosive mixtures with } \\
\text { polymer binder (plastic- } \\
\text { bonded explosives) }\end{array}$ & 15 & 3.0 & 6.0 \\
\hline \multicolumn{3}{|c|}{ Average difference of results, \% } & 1.9 & 4.5 \\
\hline
\end{tabular}

Table 2 Values of used BKW EOS parameters $[4,7]$

\begin{tabular}{|c|c|c|c|c|c|c|c|c|c|c|c|c|c|}
\hline \multirow[b]{2}{*}{$\begin{array}{l}\text { Coefficient } \\
\mathrm{s}\end{array}$} & \multirow[b]{2}{*}{$\alpha$} & \multirow[b]{2}{*}{$\beta$} & \multirow[b]{2}{*}{$\kappa$} & \multirow[b]{2}{*}{$\Theta$} & \multicolumn{9}{|c|}{ Covolumes of detonation product species, $\mathrm{k}_{\mathrm{i}}$} \\
\hline & & & & & $\begin{array}{l}\mathrm{H}_{2} \\
\mathrm{O}\end{array}$ & $\mathrm{H}_{2}$ & $\mathrm{O}_{2}$ & $\mathrm{CO}$ & $\mathrm{CO}$ & $\mathrm{NH}$ & $\mathrm{CH}$ & $\begin{array}{l}\mathrm{N} \\
\mathrm{O}\end{array}$ & $\mathrm{N}_{2}$ \\
\hline BKW-RR & $\begin{array}{l}0.51 \\
7\end{array}$ & 0.103 & 12.6 & $\begin{array}{l}188 \\
7\end{array}$ & 244 & 98 & $\begin{array}{l}40 \\
9\end{array}$ & 610 & $\begin{array}{l}42 \\
0\end{array}$ & 384 & 550 & $\begin{array}{l}38 \\
6\end{array}$ & $\begin{array}{l}44 \\
1\end{array}$ \\
\hline $\begin{array}{l}\text { BKW- } \\
\text { RDX }\end{array}$ & \multirow{2}{*}{0.5} & 0.16 & 10.91 & \multirow{2}{*}{400} & \multirow{2}{*}{250} & \multirow{2}{*}{$\begin{array}{l}18 \\
0\end{array}$} & \multirow{2}{*}{$\begin{array}{l}35 \\
0\end{array}$} & \multirow{2}{*}{600} & \multirow{2}{*}{$\begin{array}{l}39 \\
0\end{array}$} & \multirow{2}{*}{476} & \multirow{2}{*}{528} & \multirow{2}{*}{$\begin{array}{l}38 \\
6\end{array}$} & \multirow{2}{*}{$\begin{array}{l}38 \\
0\end{array}$} \\
\hline BKW-TNT & & $\begin{array}{l}0.0958 \\
5\end{array}$ & $\begin{array}{l}12.68 \\
5\end{array}$ & & & & & & & & & & \\
\hline
\end{tabular}


Table 3 Suggested usage of BKW EOS parameters and average difference of calculation results using thermochemical model [6]

\begin{tabular}{|c|c|c|c|c|c|c|}
\hline \multirow[t]{2}{*}{ No. } & \multirow[t]{2}{*}{$\begin{array}{c}\text { Used } \\
\text { parameters } \\
\text { for BKW } \\
\text { EOS }\end{array}$} & \multirow[t]{2}{*}{ High explosive composition } & \multicolumn{2}{|c|}{$\begin{array}{l}\text { Number of } \\
\text { considered } \\
\text { explosive } \\
\text { compositions }\end{array}$} & \multicolumn{2}{|c|}{$\begin{array}{c}\text { Average } \\
\text { difference of } \\
\text { calculated values } \\
\text { from } \\
\text { experimental } \\
\end{array}$} \\
\hline & & & $\mathbf{D}$ & $\mathbf{p}$ & $\Delta \mathrm{D}, \%$ & $\Delta p, \%$ \\
\hline 1. & \multirow{9}{*}{ BKW-RDX } & RDX & 13 & 10 & 1.42 & 6.62 \\
\hline 2. & & $\mathrm{RDX}+\mathrm{TNT}(<25 \%)$ & 9 & 13 & 0.82 & 2.91 \\
\hline 3. & & RDX + polymer binder $(<20 \%)$ & 6 & 2 & 0.88 & 15.70 \\
\hline 4. & & HMX & 3 & 4 & 0.78 & 2.24 \\
\hline 5. & & HMX + TNT $(<25 \%)$ & 12 & 14 & 1.65 & 3.28 \\
\hline 6. & & HMX + polymer binder $(<30 \%)$ & 18 & 8 & 3.07 & 5.24 \\
\hline 7. & & HNIW & 1 & - & 4.90 & - \\
\hline 8. & & HNIW + polymer binder $(<20 \%)$ & 1 & - & 2.40 & - \\
\hline 9. & & TET & 8 & 6 & 1.24 & 3.88 \\
\hline 10. & \multirow{6}{*}{ BKW-TNT } & RDX + TNT (25-50\%) & 26 & 17 & 1.11 & 4.68 \\
\hline 11. & & RDX + polymer binder $(20-35 \%)$ & 10 & - & 2.61 & - \\
\hline 12. & & HMX + TNT $(25-50 \%)$ & 9 & 9 & 1.15 & 5.10 \\
\hline 13. & & PETN & 2 & 4 & 3.94 & 2.39 \\
\hline 14. & & PETN + TNT $(<50 \%)$ & 11 & 9 & 3.47 & 9.26 \\
\hline 15. & & PETN + polymer binder $(<25 \%)$ & 5 & - & 1.73 & - \\
\hline 16. & \multirow{7}{*}{ BKW-RR } & TNT & 12 & 25 & 1.93 & 8.73 \\
\hline 17. & & TATB & 6 & 5 & 4.23 & 7.97 \\
\hline 18. & & HNS & 2 & 2 & 3.05 & 5.05 \\
\hline 19. & & RDX + polymer binder $(>35 \%)$ & 3 & - & 5.29 & - \\
\hline 20. & & HMX + polymer binder (> 30\%) & 4 & - & 5.54 & - \\
\hline 21. & & PETN + TNT $(>50 \%)$ & 1 & 1 & 2.09 & 9.58 \\
\hline 22. & & PETN + polymer binder $(>25 \%)$ & 10 & - & 2.06 & - \\
\hline \multicolumn{5}{|c|}{ Average difference of results, \% } & 2.05 & 5.73 \\
\hline
\end{tabular}



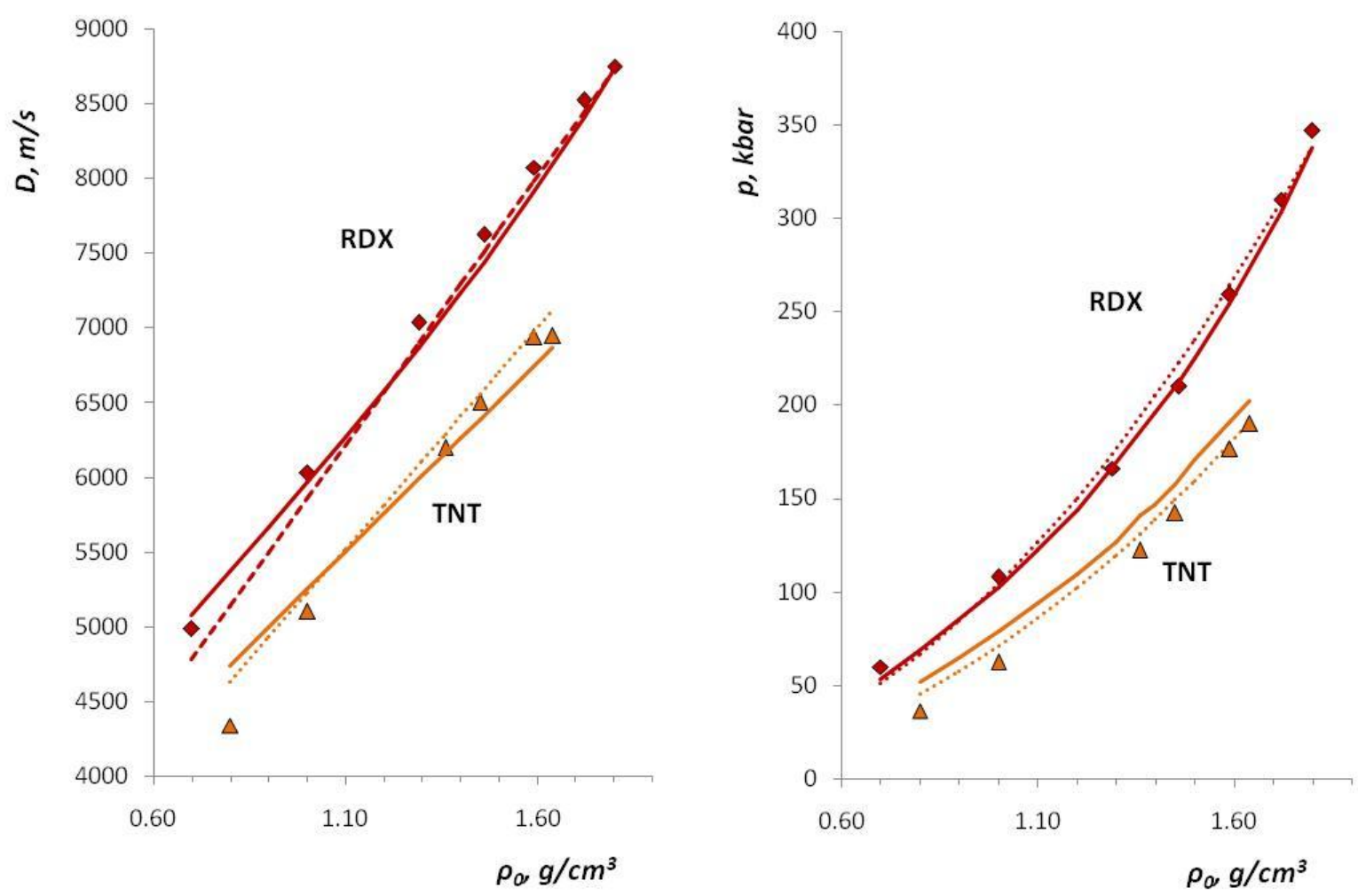

Fig. 1. Diagrams $D\left(\rho_{0}\right)$ and $p\left(\rho_{0}\right)$ for RDX and TNT
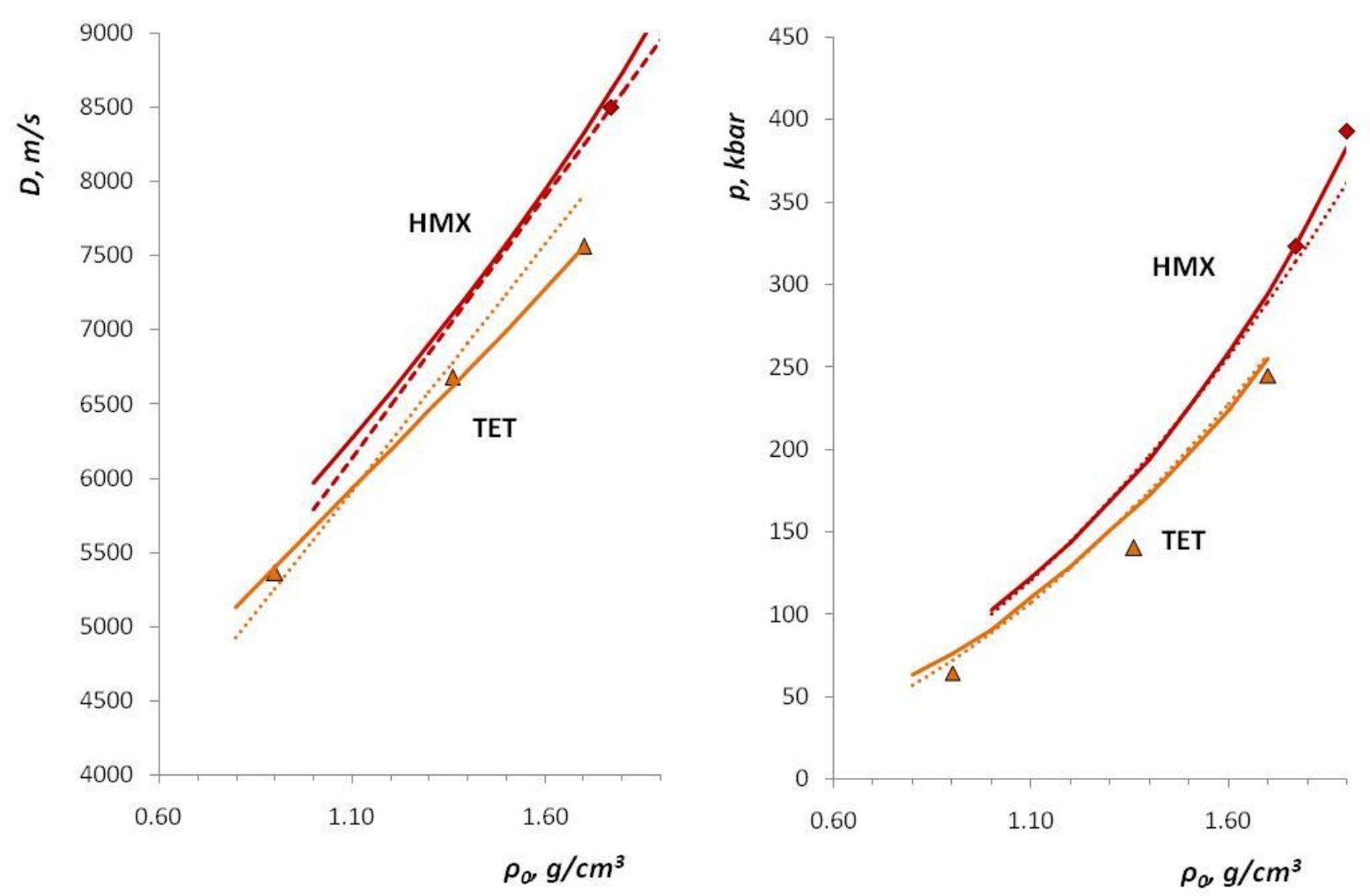

Fig. 2. Diagrams $D\left(\rho_{0}\right)$ and $p\left(\rho_{0}\right)$ for HMX and TET 